\title{
Enhanced Antifungal Effect of Chitosan/Pepper Tree (Schinus molle) Essential Oil Bionanocomposites on the Viability of Aspergillus parasiticus Spores
}

\author{
Ana Guadalupe Luque-Alcaraz, ${ }^{1}$ Mario Onofre Cortez-Rocha, ${ }^{1}$ \\ Carlos Arturo Velázquez-Contreras, ${ }^{2}$ Ana Lilian Acosta-Silva, ${ }^{2}$ \\ Hisila del Carmen Santacruz-Ortega, ${ }^{3}$ Armando Burgos-Hernández, \\ Waldo Manuel Argüielles-Monal, ${ }^{4}$ and Maribel Plascencia-Jatomea ${ }^{1}$

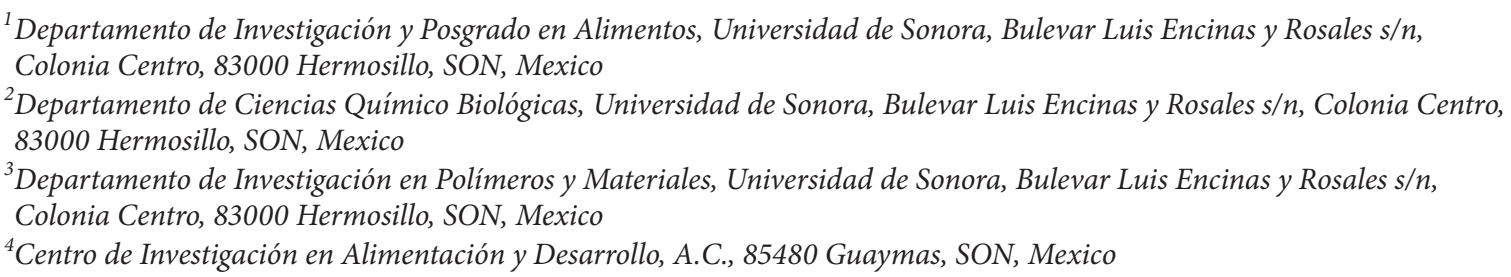

Correspondence should be addressed to Maribel Plascencia-Jatomea; mplascencia@guayacan.uson.mx

Received 10 October 2015; Revised 4 January 2016; Accepted 10 January 2016

Academic Editor: Jin-Ho Choy

Copyright (C) 2016 Ana Guadalupe Luque-Alcaraz et al. This is an open access article distributed under the Creative Commons Attribution License, which permits unrestricted use, distribution, and reproduction in any medium, provided the original work is properly cited.

\begin{abstract}
Chitosan nanoparticles (CS) and chitosan/pepper tree (Schinus molle) essential oil (CS-EO) bionanocomposites were synthesized by nanoprecipitation method and the in vitro antifungal activity against Aspergillus parasiticus spores was evaluated. The shape and size were evaluated by scanning electron microscopy (SEM) and dynamic light scattering (DLS). The surface charge was determined by assessing the zeta potential and the inclusion of essential oil in bionanocomposites using Fourier transform infrared spectroscopy (FT-IR). The effect on cell viability of the fungus was evaluated using the XTT technique and morphometric analysis by image processing. SEM and DLS analysis indicated that spherical particles with larger diameters for CS-EO biocomposites were observed. Zeta potential values were higher $(+11.1 \pm 1.60 \mathrm{mV})$ for CS nanoparticles. Results suggest a chemical interaction between chitosan and pepper tree essential oil. The highest concentration of CS-EO complex caused a larger (40-50\%) decrease in A. parasiticus viability. The inclusion of pepper tree oil in CS nanoparticles is a feasible alternative to obtain antifungal biocomposites, where the activity that each compound presents individually is strengthened.
\end{abstract}

\section{Introduction}

Environmental risks to humans, flora, and fauna have increased significantly in recent years due to excessive use of chemical fungicides and the development of resistance in species of pathogenic fungi due to the indiscriminate use of chemical agents [1]. The genus Aspergillus is widely distributed in nature as a saprophytic microorganism and can be found in fruits, vegetables, or other substrates rich in carbon sources. Some species are significantly involved in food spoilage, such as Aspergillus flavus and Aspergillus parasiticus, which produce secondary metabolites or mycotoxins that are toxic agents and carcinogenic and cause some diseases in animals and humans [2].

Mycotoxins have brought about great impact to crops, animals, and humans, since the fungus can attack agricultural products during the growth of plants at harvest or during storage. Thus, due to the increasing amounts of fungicides used for preventive and corrective control of microorganisms, the above has resulted in the need to use alternative 
fungicides that are environmentally friendly and pose no health risk. Essential oils (EOs) of plants contain a number of bioactive compounds and are widely used in food, cosmetics, and industry because of their antioxidant properties and antibacterial and antifungal activity [3-5]. Additionally, they constitute an important group of plant products that provide the characteristic odors of the aromatic plants from which they were extracted.

Essential oils are aromatic vegetable oily liquids comprising a mixture of volatile monoterpenes of low molecular weight, sesquiterpenes, and other isoprenes [6].

Schinus molle (Anacardiaceae) is a plant whose essential oil has antimicrobial properties also commonly called pepper tree [7]. Native to South and Central America, this plant has acclimated to the most tropical and subtropical areas around the world, showing usefulness in various applications [8]. The effectiveness of its essential oil against filamentous fungi has been shown and it has been proven to affect the process of germination and mycelial growth of Fusarium solani [9]; in the case of Aspergillus flavus, mycelial inhibition of up to $53.5 \%$ was found when applying a concentration of 500 ppm of pepper tree essential oil [10]. It has also exhibited antifungal activity against $A$. japonicus, $A$. niger, and $A$. oryzae through diffusion tests using disks impregnated with $5 \mu \mathrm{L}$ of oil, finding inhibition halos between 6.3 and $7.3 \mathrm{~mm}$ [11]. Similarly, Alanís-Garza et al. [12] found a minimum inhibitory concentration of $>1000 \mathrm{mg} / \mathrm{mL}$ of the oil when testing inhibition of Aspergillus fumigatus.

Regarding toxicity, it has been reported that, at concentrations of 4.3 and $5.6 \%(\mathrm{w} / \mathrm{v})$, the aqueous extract of pepper tree caused a mortality of $27 \%$ of the Xanthogaleruca luteola Müller insect [13]. Furthermore, when evaluating the mutagenic activity of the essential oil extracted from pepper tree leaves, a high level of toxicity of Artemia salina was found, reaching $\mathrm{LC}_{50}$ values of $47 \mu \mathrm{g} / \mathrm{mL}$, while the standard potassium dichromate presented $\mathrm{LC}_{50}$ of $50 \mu \mathrm{g} / \mathrm{mL}$ [11].

According to what was reported by Olafsson et al. [8], the pepper tree essential oil is rich in monoterpenes, limonene, $\beta$-phellandrene, $\alpha$-phellandrene, myrcene, and $\alpha$-pinene. However, the biological activity of oil can be lost through the volatilization of its components or due to degradation when exposed to light, heat, and/or pressure [14, 15]. Among the emerging alternatives to solve this problem is nanotechnology, in which many essential oils have been encapsulated such as eugenol [16], Mentha piperita oils [14], Lippia sidoides essential oils [17], thyme oil [18], and pepper tree essential oil [7]. Moreover, by forming nanoparticles, components of essential oils have been encapsulated or embedded in polymer matrices and one of the materials that has proven effective for the encapsulation of these active compounds is chitosan [19].

Chitosan is a polymer obtained from the deacetylation of chitin, a polysaccharide of natural and abundant source, which is second in abundance after cellulose. The use of chitosan for the encapsulation of various active components has gained attention in recent years due to its mucoadhesive properties, biocompatibility, biodegradability, and low or no toxicity [20]. Recently, there have been numerous studies published on the encapsulation of essential oils in chitosan with the main objective of increasing its stability and preserving the functional properties of oils such as eugenol [16], Elsholtzia splendens extract [21], oregano essential oil [22], and carvacrol [23].

Hosseini et al. [22] synthesized chitosan and chitosan loaded with oregano essential oil nanoparticles, finding that systems obtained had particle diameters of 281.5 and 309.8-402.2 nm, respectively, having a directly proportional relationship between the amount of oil loaded in the particle and its size. Similar results were reported by Woranuch and Yoksan [24], who synthesized chitosan nanoparticles with diameters of $586 \mathrm{~nm}$ and chitosan nanoparticles loaded with eugenol with diameters in the range of 726-760 nm.

Regarding the antifungal activity of chitosan as nanoparticles, it has been shown that these materials are active against some fungi proving chitosan nanoparticles' antifungal potential, as shown in Table 1.

In relation to previous research, the antifungal properties of chitosan nanoparticle systems coupled to various essential oils are evident. However, to date, there are no previous studies that evaluate the effect of chitosan nanoparticles loaded with pepper tree oil (Schinus molle) on the growth of toxigenic filamentous fungi of relevance in food. The aim of this research was to obtain chitosan nanoparticles and chitosan/pepper tree essential oil to evaluate its effect on viability and morphometry of Aspergillus parasiticus spores.

\section{Materials and Methods}

2.1. Pepper Tree (Schinus molle) Essential Oil Extraction. The essential oil of pepper tree (Schinus molle) was extracted by hydrodistillation, for 4 hours at $100^{\circ} \mathrm{C}$, from pepper tree leaves collected from the Yaqui Valley, Sonora, Mexico $\left(27^{\circ} 34^{\prime \prime} 39 \mathrm{~N}\right.$ and $\left.109^{\circ} 56^{\prime \prime} 19 \mathrm{O}\right)$, during the month of August 2013. The leaves were dried in the shade for a week at room temperature. For extraction, $100 \mathrm{~g}$ of dry leaves and $1000 \mathrm{~mL}$ of distilled water were placed in a device equipped with trap type Clevenger (IMPARLAB, Mexico), a heating jacket (CIVEQ, Mexico), and a cooling system (LAUDA Alpha 8, USA).

2.2. Inoculum Preparation. Aspergillus parasiticus strain (ATCC 16992) was used, selected based on its importance in food for being a toxin producing species. The strain was activated in potato dextrose agar (PDA, Bioxon, USA) acidified with tartaric acid $(10 \% \mathrm{w} / \mathrm{v})$ and incubated for 5 days at $25 \pm 2^{\circ} \mathrm{C}$. Developed spores were resuspended by adding sterile Czapek liquid culture medium, stirring with a sterile magnetic bar for $1 \mathrm{~min}$. The concentration of the spore suspension was determined by count in a Neubauer chamber (Brand, Germany) and the inoculum was adjusted to a concentration of $4 \times 10^{6}$ spores $/ \mathrm{mL}$.

2.3. Nanoparticles Preparation. Commercial chitosan (Sigma-Aldrich, USA) with a degree of $\mathrm{N}$-acetylation (DA) of 0.178 and a viscometric molecular weight of $1.1 \times 10^{5} \mathrm{kDa}$ (estimated at $25^{\circ} \mathrm{C}$ in $0.3 \mathrm{M}$ acetic acid and $0.2 \mathrm{M}$ sodium acetate) was used for the synthesis of nanoparticles [25]. 
TABLE 1: Antifungal activity of chitosan-based nanoparticles.

\begin{tabular}{|c|c|c|c|c|}
\hline Chitosan properties & Synthesis method & Microorganism & Antimicrobial activity & Reference \\
\hline Low $M w(70 \mathrm{kDa}), 75-85 \%$ & \multirow[b]{2}{*}{ Ionic gelation } & \multirow[b]{2}{*}{$\begin{array}{l}\text { Candida albicans } \\
\text { Aspergillus niger } \\
\text { Fusarium solani }\end{array}$} & $\begin{array}{l}\text { Linear relation between chitosan } \\
\text { molecular weight and particle }\end{array}$ & \multirow[b]{2}{*}[27]{} \\
\hline $\begin{array}{l}\text { High } M w(310 \mathrm{kDa}), 85 \% \\
\text { DD }\end{array}$ & & & $\begin{array}{l}\text { size } \\
\mathrm{MIC}_{90} \text { value to inhibit C. albicans } \\
\text { diminishes when the chitosan } \\
\text { concentration increases }\end{array}$ & \\
\hline $\begin{array}{l}\text { Low } M w \text {, cinnamic acid, } \\
\text { Mentha piperita }\end{array}$ & Precipitation & Aspergillus flavus & $\begin{array}{l}\text { The quality of tomato fruit is } \\
\text { preserved for } 30 \text { days }\end{array}$ & {$[14]$} \\
\hline $\begin{array}{l}\text { High } M w(684 \mathrm{kDa}), 85 \% \\
\text { DD } \\
\text { Zataria multiflora essential } \\
\text { oil }\end{array}$ & Ionic gelation & Botrytis cinerea & $\begin{array}{c}\text { The chitosan/Zataria multiflora } \\
\text { essential oil nanoparticles } \\
\text { showed an increased antifungal } \\
\text { activity }\end{array}$ & {$[28]$} \\
\hline $\begin{array}{l}\text { Low } M w(160 \mathrm{kDa}), 85 \% \\
\mathrm{DD} \\
\text { Kappa carrageenan, } \\
\text { Pimenta dioica essential oil }\end{array}$ & Oil-in-water emulsion & $\begin{array}{l}\text { Bacillus subtilis } \\
\text { B. cereus } \\
\text { Aspergillus niger } \\
\text { and others }\end{array}$ & $\begin{array}{c}\text { The growth was inhibited until } \\
70 \% \text { with } 50 \mu \mathrm{g} / \mathrm{mL} \text { of } \\
\text { nanoparticles }\end{array}$ & [29] \\
\hline
\end{tabular}

TABle 2: Nomenclature used to describe the concentration of both chitosan nanoparticles and chitosan/pepper tree essential oil biocomposites.

\begin{tabular}{|c|c|c|c|c|c|c|}
\hline \multicolumn{2}{|c|}{ Pepper tree essential oil (EO) } & \multicolumn{2}{|c|}{ Chitosan nanoparticles (CS) } & \multicolumn{3}{|c|}{ Chitosan/EO bionanocomposites (CSEO) } \\
\hline Treatment & $\begin{array}{l}\text { EO concentration } \\
(\mu \mathrm{g} / \mathrm{mL})\end{array}$ & Treatment & $\begin{array}{c}\text { Chitosan } \\
\text { concentration } \\
(\mu \mathrm{g} / \mathrm{mL})\end{array}$ & Treatment & $\begin{array}{c}\text { EO concentration } \\
(\mu \mathrm{g} / \mathrm{mL})\end{array}$ & $\begin{array}{c}\text { Chitosan } \\
\text { concentration } \\
(\mu \mathrm{g} / \mathrm{mL})\end{array}$ \\
\hline EO-A & 200 & CS-A & 150.9 & CSEO-A & 200 & 150.9 \\
\hline $\mathrm{EO}-\mathrm{B}$ & 100 & CS-B & 75.5 & CSEO-B & 100 & 75.5 \\
\hline $\mathrm{EO}-\mathrm{C}$ & 50 & $\mathrm{CS}-\mathrm{C}$ & 37.7 & CSEO-C & 50 & 37.7 \\
\hline EO-D & 25 & CS-D & 18.9 & CSEO-D & 25 & 18.9 \\
\hline $\mathrm{EO}-\mathrm{E}$ & 12.5 & CS-E & 9.4 & CSEO-E & 12.5 & 9.3 \\
\hline Control & 0 & Control & 0 & Control & 0 & 0 \\
\hline
\end{tabular}

Nanoparticles were obtained using the nanoprecipitation method according to the procedure described by LuqueAlcaraz et al. [26]. $2.5 \mathrm{~mL}$ of a chitosan solution $0.5 \%(\mathrm{w} / \mathrm{v})$ was taken and added to $40 \mathrm{~mL}$ of methanol (Sigma-Aldrich, USA) containing or not pepper tree oil extract (Schinus molle) at a concentration of $0.05 \%(\mathrm{v} / \mathrm{v})$. The process was made under magnetic stirring $(500 \mathrm{rpm})$ and with a flow of $0.87 \mathrm{~mL} / \mathrm{min}$ with a peristaltic pump (Gilson Minipuls 3, France). Subsequently, methanol was removed by rotary evaporation (Labconco rotary evaporator 78892, USA) connected to a coolant (Yamato, USA) until a volume less than $10 \mathrm{~mL}$ of the initial sample was obtained. The obtained nanoparticles were diluted to different concentrations to achieve the applied treatments (Table 2). The systems obtained were characterized as described below.

\subsection{Nanoparticles and Bionanocomposites Characterization}

2.4.1. Scanning Electron Microscopy. The morphology of the samples was studied by scanning electron microscopy in SEM SIGMA HD VP from Carl Zeiss microscope.

2.4.2. FT-IR Analysis. The interaction between chitosan and the essential oil was analyzed by FT-IR spectra and was obtained using Perkin-Elmer FT-IR Spectrum GX with an average of sixteen scans in a spectral range of $4000-400 \mathrm{~cm}^{-1}$. The analysis was carried out in liquid media.

2.4.3. Size and Zeta Potential. The dispersion of size and zeta potential of nanoparticles of chitosan and chitosan/pepper tree essential oil bionanocomposites was measured using Möbius equipment (Wyatt Technology, Santa Barbara, CA, USA) with a laser wavelength of $532 \mathrm{~nm}$ and scattering angle of $90^{\circ}$, for which samples were prepared with Milli$\mathrm{Q}$ water and vortexed for 15 seconds before measurement. Measurements were performed in triplicate at a temperature of $25^{\circ} \mathrm{C}$.

\subsection{Antifungal Assay}

2.5.1. Spore Viability. A colorimetric assay for the quantification of the number of viable spores was conducted using salt XTT 2,3-Bis(2-methoxy-4-nitro-5-sulfophenyl)-5-[(phenylamino)carbonyl]-2H-tetrazolium hydroxide (Sigma-Aldrich, USA). The assay was carried out in the presence of menadione as electron-coupling agent [30].

Spore suspension was prepared at a concentration of $4 \times$ $10^{6}$ spores/mL in Czapek liquid medium and stirred using a 
magnetic stirrer; $100 \mu \mathrm{L}$ of spore suspension was taken to be inoculated on 96-well flat-bottom microplate (Costar, Corning, USA) to obtain a final concentration of $2 \times 10^{6}$ spores $/ \mathrm{mL}$ in each well. The plates were incubated (Nova-Tech, USA) for 4 hours at $27 \pm 2^{\circ} \mathrm{C}$ and were removed and $100 \mu \mathrm{L}$ of each nanoparticle treatment was added to each well, incubating again at the same conditions for another 4 hours. Following the elapsed time, the plates were removed again and $50 \mu \mathrm{L}$ of XTT solution and $7 \mu \mathrm{L}$ of menadione solution were added to each well to obtain a final concentration of $400 \mu \mathrm{g}$ of XTT and $25 \mu \mathrm{M}$ of menadione [30]. The microplates were incubated again for another 3 hours at $27 \pm 2^{\circ} \mathrm{C}$ and the optical density was measured at $450 \mathrm{~nm}\left(\mathrm{OD}_{450 \mathrm{~nm}}\right)$ with a spectrophotometer (ThermoLab Systems, China). The XTT assay was performed in triplicate and the OD was assessed after 3 hours of exposure to the spores of the fungus in the presence of the nanoparticulate systems.

2.5.2. Morphometric Parameters of Spores. The average diameter of the fungi spores was measured by image analysis, which was obtained using an optical microscope (Olympus CX31, Japan) connected to an Infinity 1 camera (Media Cybernetics, USA) using 40x objective. The images were analyzed using Image-Pro Plus software version 6.3 (2008 Media Cybernetics Inc., USA) [31]. At least 50-60 measurements were taken per each treatment.

2.6. Statistical Analysis. Statistics on a completely randomized design were determined using the one-way analysis of variance (ANOVA) at a level of significance set at $P=0.050$. Means for groups in homogeneous subsets were carried out using the Tukey multiple comparisons test (Tukey's post hoc test), at $95 \%$ confidence interval. All data were presented as mean value with their standard error indicated (mean $\pm \mathrm{SE}$ ). Differences were accepted as significant when $P \leq 0.05$.

\section{Results and Discussion}

3.1. Morphology of Bionanocomposites. According to SEM analysis, chitosan nanoparticles and chitosan/pepper tree essential oil bionanocomposites showed a regular size distribution and a spherical shape with no evidence of agglomerates formation. The size of the chitosan nanoparticles was in the range 20-100 $\mathrm{nm}$ (Figure 1(a)), while the chitosan/pepper tree oil bionanocomposites were in the range $200-600 \mathrm{~nm}$ (Figure 1(b)). The fact that the diameter of chitosan/pepper tree oil particles is greater than that of the chitosan nanoparticles can be attributed to several factors, such as the swelling of the chitosan layer surrounding the individual particles or the aggregation of the particles while dispersed in water [23]. Some authors have reported that the size of the nanoparticles can be decreased through several procedures: first, initial sonication, which can convert the long chains of chitosan into small pieces and prevent the formation of agglomerates; second, resonication; and third, making the nanoparticles pass through filters [18].

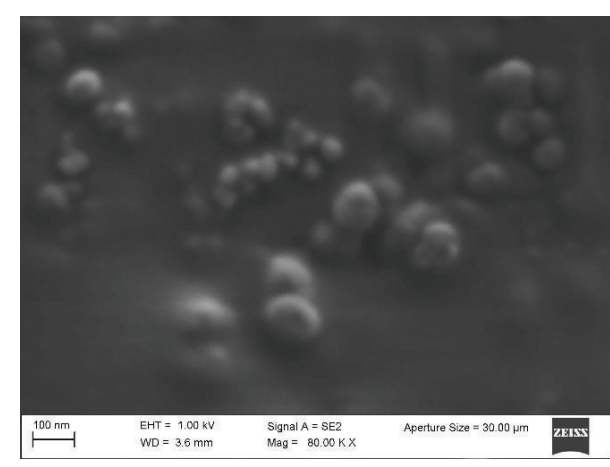

(a)

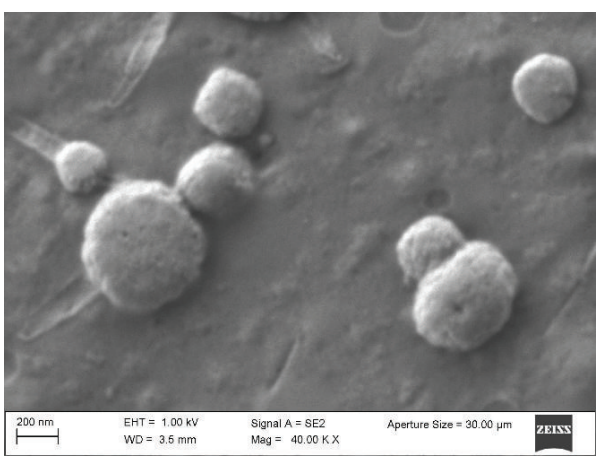

(b)

FIGURE 1: SEM images of nanoparticles: (a) chitosan nanoparticles and (b) chitosan/pepper tree essential oil biocomposite nanoparticles.

\subsection{Physicochemical Characterization}

3.2.1. Fourier Transform Infrared Spectroscopy (FTIR). Fourier transform infrared spectroscopy (FT-IR) is a technique for identifying the chemical composition of a material, which provides valuable information to show the measured coupling through intra- and intermolecular chemical interactions between components of chitosan and pepper tree essential oil bionanocomposites. In Figure 2(a), distinctive bands of chitosan spectrum can be seen, showing the bending band of the amino group $\left(\mathrm{NH}_{2}\right)$ at $1600 \mathrm{~cm}^{-1}$. Meanwhile, in Figure 2(b), a band at $1750 \mathrm{~cm}^{-1}$ was observed, which is related to the carbonyl group $\mathrm{C}=\mathrm{O}$ present in some terpenes molecules of essential oils constituents. In Figure 2(c), chitosan/oil pepper tree bionanocomposites spectrum is shown and the disappearance of the carbonyl signal $(\mathrm{C}=\mathrm{O})$ when carrying out the reaction with the amino groups of chitosan can be observed. It is accurate to assume that when the reaction occurs, the decreasing of the vibration frequency of the bands distinctive to chitosan is associated with the formation of an amino group detected between 1640 and $1690 \mathrm{~cm}^{-1}$. Similar results have been found when coupling molecules of essential oils components to chitosan nanoparticles. By modifying carvacrol and eugenol with aldehyde groups to react with chitosan nanoparticles through Schiff base, reduced intensity of bands $\mathrm{NH}$ and $\mathrm{C}=\mathrm{O}$ was detected when compared with spectrum signals of 


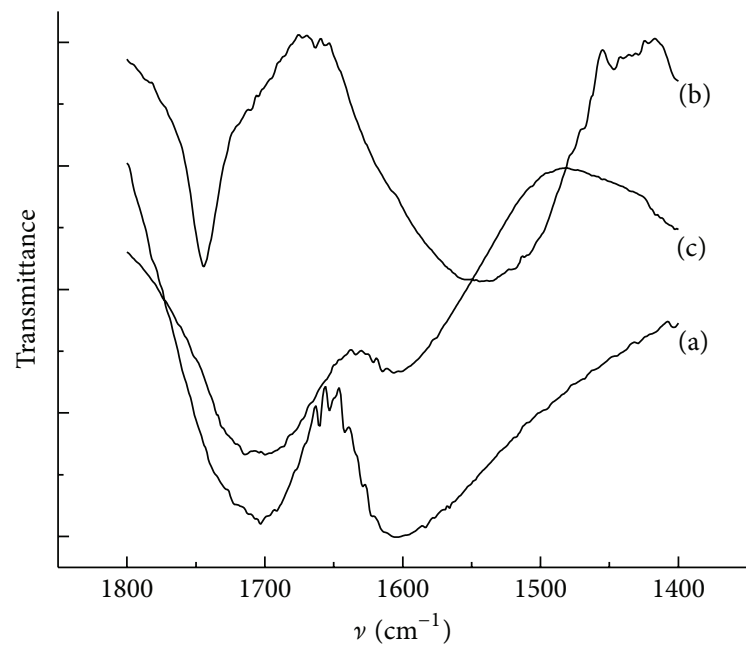

FIGURE 2: Fourier transform infrared spectroscopy (FT-IR) analysis obtained for (a) chitosan nanoparticles, (b) pepper tree essential oil, and (c) chitosan/pepper tree essential oil bionanocomposites.

TABLE 3: Zeta potential of chitosan nanoparticles and chitosan/ pepper tree essential oil bionanocomposites.

\begin{tabular}{lcc}
\hline System & Diameter $(\mathrm{nm})$ & Zeta potential $(\mathrm{mV})$ \\
\hline CS Np & $494 \pm 168^{\mathrm{a}}$ & $+11.1 \pm 1.60^{\mathrm{a}}$ \\
CS EO Np & $754 \pm 7.5^{\mathrm{b}}$ & $+9.1 \pm 1.74^{\mathrm{a}}$ \\
\hline
\end{tabular}

Data, followed by their standard errors, are means of at least three experiments. Treatment means were separated using the Tukey test $(P>0.05)$. Different letters in superscript indicate significant differences $(P<0.05)$.

pure chitosan nanoparticles. This decrease can be attributed to the reduction of amino groups on the surface of the nanoparticles, resulting from this bond $-\mathrm{C}=\mathrm{N}-$ [32]. Chitosan has both reactive amino and hydroxyl groups; the amino group leads to the possibility of several chemical modifications, including Schiff bases $(-\mathrm{RC}=\mathrm{N}-)$ by reactions with aldehydes and ketones [33]. In a study carried out by Luque-Alcaraz et al. [26], in which the inclusion of flavonoids into the nanoparticle system was evaluated, the infrared spectrum of nobiletin-chitosan nanoparticles was obtained. This spectrum exhibited important bands at $1626 \mathrm{~cm}^{-1}$, which are associated with the probable formation of an imine bond between chitosan amine groups and the carbonyl group of nobiletin, via Schiff-base formation. In the characterization of chitosan Schiff bases, new absorption peaks appear at 1648.3 and $1610.6 \mathrm{~cm}^{-1}$, corresponding to the $\mathrm{C}=\mathrm{N}$ vibration characteristic of imine group [33].

3.2.2. Zeta Potential and Size. Figure 3 shows the size dispersion of chitosan nanoparticles (a) and chitosan/pepper tree bionanocomposites (b). Chitosan nanoparticles had a diameter of $494 \pm 168 \mathrm{~nm}$ and a zeta potential of $+11.1 \pm$ $1.60 \mathrm{mV}$, while chitosan/pepper tree bionanocomposites presented a larger diameter $(754 \pm 7.5 \mathrm{~nm})$ and zeta potential of $+9.1 \pm 1.74 \mathrm{mV}$ (Table 3). Similar results were reported by Woranuch and Yoksan [24], who obtained nanoparticles of chitosan and chitosan/eugenol with diameters of 586

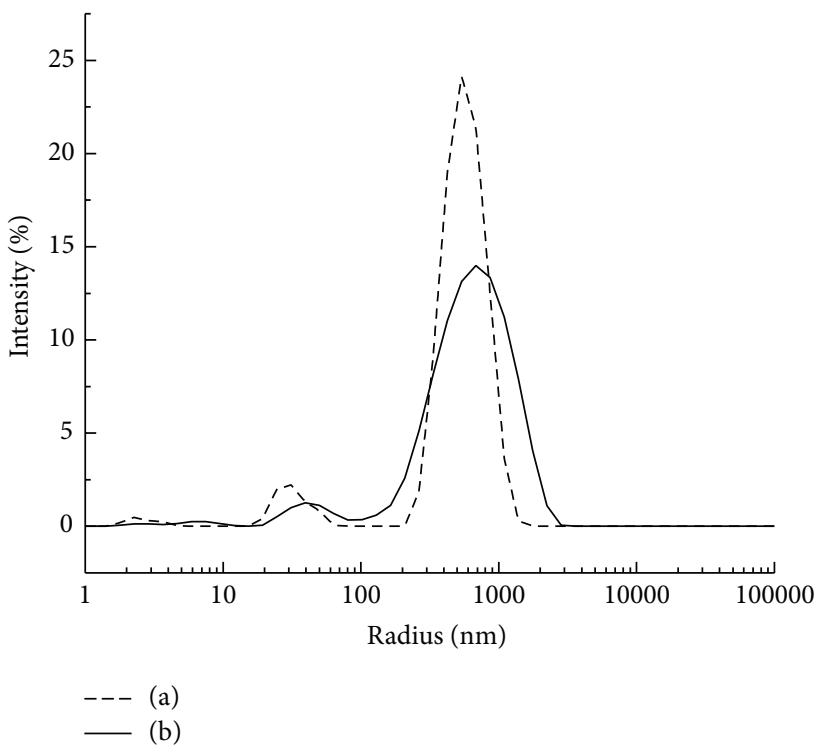

FIGURE 3: Particle size distribution by intensity of chitosan nanoparticles (a) and chitosan/pepper tree essential oil bionanocomposites (b).

and $726-760 \mathrm{~nm}$, respectively. A comparison between the nanoparticles size obtained by SEM and that measured by dynamic light scattering (DLS) indicated differences in this parameter. This outcome could be due to the sampling process. For SEM evaluation, the sample is dry prepared and the size is individually measured [34]. On the other hand, for DLS, the sample is in solution and the result is size dispersion of the nanoparticles. Similar results were reported by Woranuch and Yoksan [16]. They obtained nanoparticles with a size of 80-100 $\mathrm{nm}$ (TEM) and 586-683 $\mathrm{nm}$ (using DLS) for the same preparation of chitosan-eugenol nanoparticles. It should be noted that the larger size of particles obtained by DLS, compared to those from TEM, might be a result of the nanoparticle swelling and aggregation during its dispersion in an aqueous medium. In addition, in a study by Zhang and Zhao [35], nanoparticles showed smaller particle size based on Atomic Force Microscopy than that measured by DLS, which could be explained by the fact that the chitosan nanoparticles were not in a hydrated state; thus, they were not expanded as they were for the DLS measurements.

The zeta potential is the charge on the surface of the suspended particles and the electrostatic repulsion between the particles can greatly influence its stability when kept in suspension [36]. Research done determined that chitosan nanoparticles ( $\mathrm{CsNp}$ ) showed a zeta potential of $+11.1 \pm$ $1.60 \mathrm{mV}$, at a concentration of $0.0005 \mathrm{~g} / \mathrm{mL}$. This value is lower compared to that obtained by Woranuch and Yoksan [16], who synthesized nanoparticles with an approximate concentration of $0.48 \mathrm{~g} / \mathrm{mL}$ chitosan and $0.5 \%(\mathrm{w} / \mathrm{v})$ sodium tripolyphosphate (TPP) as cross-linking agent, with zeta potential values of $+37.7 \mathrm{mV}$. This difference can be attributed to the concentration of nanoparticles in the solution when performing the evaluation. 


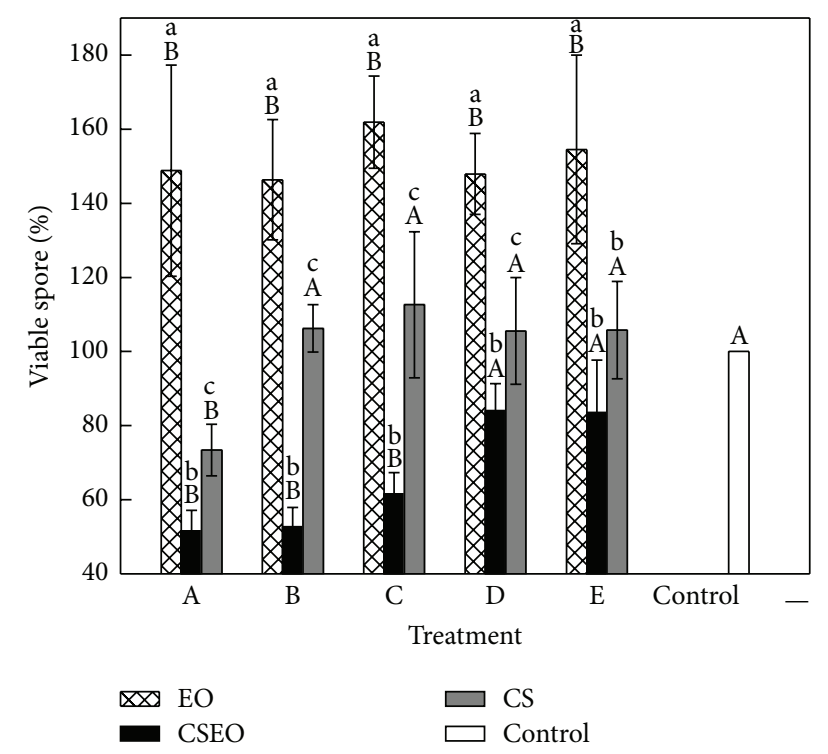

FIGURE 4: Viability of spores of Aspergillus parasiticus grown in Czapek liquid media with added pepper tree essential oil (EO), chitosan nanoparticles (CS), and chitosan/pepper tree essential oil (CSEO), at $27 \pm 2{ }^{\circ} \mathrm{C}$. ${ }^{*}$ The bars represent the mean \pm standard deviation of 3 treatments at 5 different concentrations tested. ${ }^{*}$ Different lowercase letters show significant differences $(P<0.05)$ between the treatments of the same concentration. Different capital letters represent significant differences $(P<0.05)$ between the concentrations of the 3 treatments and control.

The effect of concentration on the value of zeta potential has been studied by Ing et al. [27] who found a directly proportional relationship between the concentration of the nanoparticles and the zeta potential thereof. The positive surface charge results from protonation of the amino groups of chitosan; however, such potential decreases when loading the nanoparticles with essential oil, which can be attributed to an effect of shielding the positive charges from the essential oil. In this study, no differences $(P>0.05)$ in the values of zeta potential were found, which can also be attributed to some encapsulation effect of the oil within the chitosan molecular network that forms chitosan/pepper tree bionanocomposites. Nonetheless, the fact of presenting positive charges is indicative of stability from both chitosan nanoparticles and chitosan/pepper tree bionanocomposites, because the electrostatic repulsion between particles remains $[35,37]$. Similarly, due to the positive charge system, it is possible that these interact with phospholipids of the fungi membrane, destabilizing it and causing the output of intracellular components, with consequent death of cells $[27,36]$.

\subsection{Antifungal Assay}

3.3.1. Cell Viability. Some authors have reported good correlation between the results obtained by XTT assay and standardized methods ASTM D4445-10 and AWPA E24 (12-week testing duration) when assessing the viability of filamentous fungi spores such as Penicillium chrysogenum, Trichoderma atroviride, Aspergillus niger, and Candida albicans [38, 39].
During this study, while evaluating the effect of different concentrations of pepper tree essential oil (S. molle), it was revealed that all treatments applied increased the viability percentage of the spores of the fungus in relation to the control $(P<0.05)$ (Figure 4); nonetheless, no differences $(P>0.05)$ were found between the different concentrations employed: $200 \mu \mathrm{g} / \mathrm{mL}$ (EO-A), $100 \mu \mathrm{g} / \mathrm{mL}$ (EO-B), $50 \mu \mathrm{g} / \mathrm{mL}$ (EO-C), $25 \mu \mathrm{g} / \mathrm{mL}$ (EO-D), and $12.5 \mu \mathrm{g} / \mathrm{mL}$ (EO-E).

In 1986, Dikshit et al. [10] evaluated the antifungal effect of pepper tree essential oil (extracted by hydrodistillation) on mycelial growth of Aspergillus flavus, finding inhibition of $53.5 \%$ when applying a concentration of $500 \mu \mathrm{g} / \mathrm{mL}$. This concentration is higher compared to those used in our study, which explains the strong inhibitory effect found by the authors.

In the essential oil from pepper tree leaves, about 22 components have been identified, featuring monoterpenes (69.3\%) and sesquiterpenes (17\%), to which antimicrobial activity is attributed on Enterococcus faecalis, Staphylococcus epidermidis, S. aureus, Pseudomonas aeruginosa, and Escherichia coli and antifungal activity is attributed on Aspergillus niger, A. japonicus, A. oryzae, Fusarium oxysporum, Rhizopus oryzae, and R. stolonifer [11]. Similarly, it has proven effective as biopesticide against Xanthogaleruca luteola, reaching nearly $100 \%$ mortality at concentrations of $4.3-4.7 \mathrm{mg} / \mathrm{mL}$ [13].

XTT technique has been previously reported to examine the antibacterial effect of Paronychia argentea and Varthemia iphionoides extracts on proliferation of Bacillus subtilis, Staphylococcus aureus, Escherichia coli, and Pseudomonas aeruginosa [40]. It has also been employed to analyze the effect of copper nanoparticles on the viability of filamentous fungi such as Alternaria alternata, Aspergillus flavus, Fusarium solani, and Penicillium chrysogenum [41]. Figure 4 presents the results of the effect of different concentrations of chitosan nanoparticles on the viability of Aspergillus parasiticus spores. No differences $(P>0.05)$ between treatments CSB $(75.95 \mu \mathrm{g} / \mathrm{mL})$, CS-C $(37.72 \mu \mathrm{g} / \mathrm{mL})$, CS-D $(18.86 \mu \mathrm{g} / \mathrm{mL})$, and CS-E $(9.43 \mu \mathrm{g} / \mathrm{mL})$ were found with respect to control, at 4 hours of exposure to nanoparticles. However, at the highest concentration tested (CS-A, $150.9 \mu \mathrm{g} / \mathrm{mL}$ ), a decrease $(P<0.05)$ of $30 \%$ of cell viability relative to other treatments including the control was found.

Regarding the study of chitosan/pepper tree essential oil bionanocomposites, it was established that all treatments reduced the viability of fungal spores from control $(P<0.05)$ (Figure 4), having a smaller number of viable spores in the treatment with higher concentrations of chitosan/pepper tree bionanocomposites. Some authors have demonstrated the effect of the concentration of Cuminum cyminum essential oil coupled to chitosan-caffeic acid nanoparticles in the growth or viability of filamentous fungi such as Aspergillus flavus [42]. It was also found that the nanoparticles of chitosancaffeic acid Cuminum cyminum showed an antifungal action directly proportional to the concentration of nanoparticles applied.

The results obtained demonstrate the antifungal potential of chitosan/pepper tree oil bionanocomposites on the viability of spores of Aspergillus parasiticus, which can be 


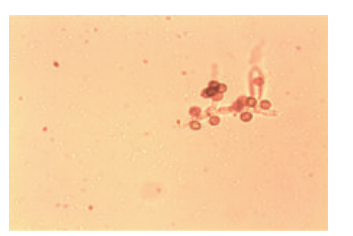

EO-A

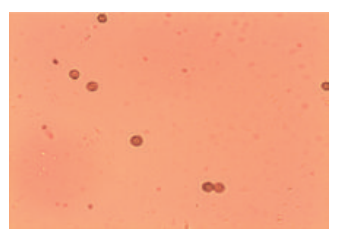

CS-A

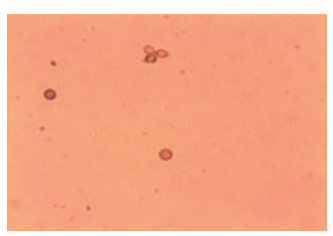

CSEO-A

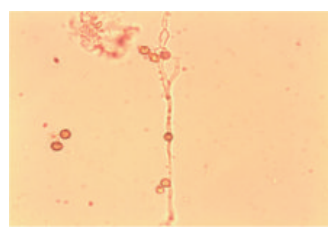

EO-B

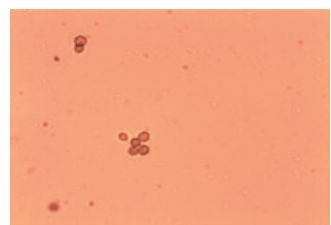

CS-B

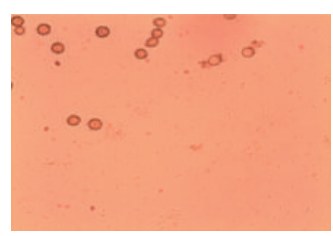

CSEO-B

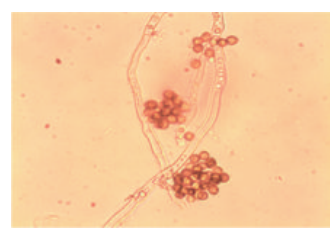

EO-C

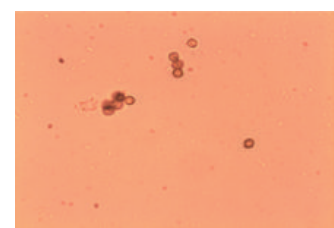

CS-C

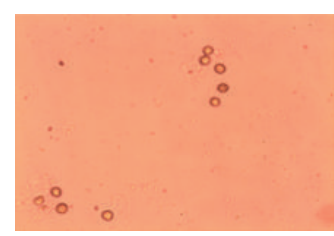

CSEO-C

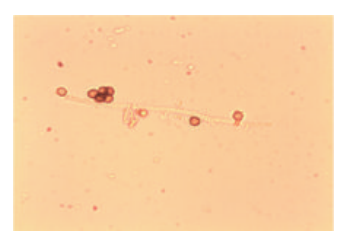

EO-D

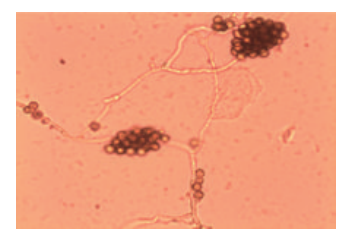

CS-D

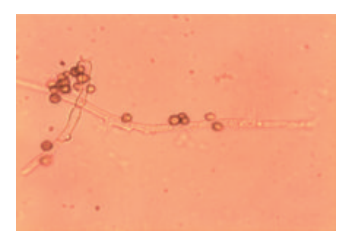

CSEO-D

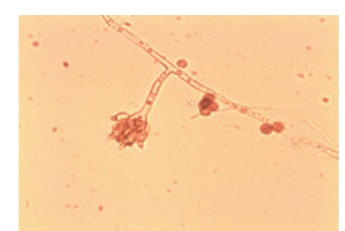

EO-E

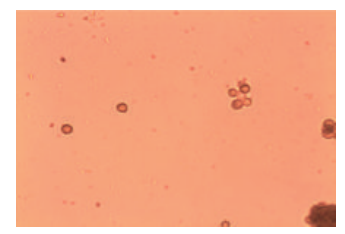

CS-E

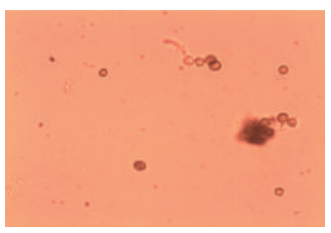

CSEO-E

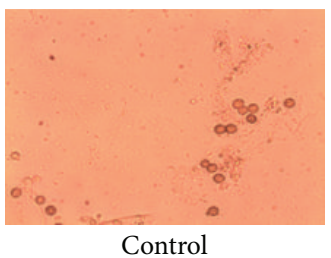

Figure 5: Spores of Aspergillus parasiticus grown in Czapek liquid media with added pepper tree essential oil (EOA, B, C, D, and E), chitosan nanoparticles (CS-A, B, C, D, and E), chitosan/pepper tree essential nanoparticles (CSEO-A, B, C, D, and E), and control, at 8 hours after inoculation, at 40x.

attributed to electrostatic interactions of Van der Waals type and hydrogen bonds between the negatively charged components present in the fungus cell membrane and the positive charge of the bionanocomposites. It has been proven that the electrostatic interactions between positively charged nanoparticles and microbial cell membrane can cause membrane destabilization, altering the properties thereof and causing the death of the microorganisms [43].

Possible mechanisms associated with the effect of essential oils on the growth of fungi have been published in various studies. Rasooli and Abyaneh [44] demonstrated that thymol oil inhibits mycelial growth of Aspergillus parasiticus, which was associated with a significant decrease in the production of aflatoxins. Similarly, the application of thymol oil (50 to $500 \mu \mathrm{g} / \mathrm{mL}$ ) showed an antifungal (from $250 \mu \mathrm{g} / \mathrm{mL}$ ) and antiaflatoxigenic (from $150 \mathrm{mg} / \mathrm{mL}$ ) effect on Aspergillus flavus, noting obvious alterations in the size of conidia and hyphae structure characterized by a decrease of cytoplasmic content and effects on the integrity of the cell membrane [45]. Comparable results have been published by other authors in evaluating the antifungal capability of other essential oils coupled to chitosan nanoparticles. Herculano et al. [19] showed that chitosan nanoparticles provide a protective effect to Cuminum cyminum essential oil, reducing its volatility and increasing its useful life $[14,18]$.
The present study demonstrates that it is feasible to couple chitosan and pepper tree essential oil to obtain antifungal bionanocomposites with a higher activity compared to the effect that both chitosan and pepper tree oil present individually.

3.3.2. Morphometric Parameters of Spores. In Figure 5, spores of Aspergillus parasiticus exposed to different treatments can be observed. The spores subjected to treatments based on pepper tree oil $(\mathrm{EO}-\mathrm{A}=200 \mu \mathrm{g} / \mathrm{mL}, \mathrm{EO}-\mathrm{B}=100 \mu \mathrm{g} / \mathrm{mL}$, EO$\mathrm{C}=50 \mu \mathrm{g} / \mathrm{mL}, \mathrm{EO}-\mathrm{D}=25 \mu \mathrm{g} / \mathrm{mL}$, and EO-E $=12.5 \mu \mathrm{g} / \mathrm{mL}$ ) and control show that the treatments did not affect the diameter of the spores. All treatments were statistically equal to the control $(P>0.05)$, as shown in Table 4 .

The antifungal effect of essential oils such as Origanum syriacum L. var. bevanii, Lavandula stoechas L. var. stoechas, and Rosmarinus officinalis L. (at concentrations of $12.5 \mathrm{y}$ $25 \mu \mathrm{g} / \mathrm{mL}$ ) on Botrytis cinerea has been documented, finding inhibition of spore germination as elongation of germinal tubule, besides morphological degeneration of hyphae characterized by cytoplasmic coagulation, vacuolations, hyphal shriveling, protoplast leakage, and loss of conidiation [46]. In Aspergillus flavus exposed to Thymus vulgaris L. essential oil $(100$ to $500 \mu \mathrm{g} / \mathrm{mL})$, there were alterations in the structures of conidiophores and hyphae, in addition to decrease of 
TABLE 4: Effect of pepper tree essential oil and nanoparticles on the spores diameter of Aspergillus parasiticus, at 8 hours, at $27 \pm 2{ }^{\circ} \mathrm{C}$.

\begin{tabular}{lccccc}
\hline Treatment & Spore diameter $(\mu \mathrm{m})$ & Treatment & Spore diameter $(\mu \mathrm{m})$ & Treatment & Spore diameter $(\mu \mathrm{m})$ \\
\hline EO-A & $23.15 \pm 0.306^{\mathrm{a}}$ & CS-A & $23.48 \pm 0.333^{\mathrm{a}}$ & CSEO-A & $22.53 \pm 0.358^{\mathrm{a}, \mathrm{b}}$ \\
EO-B & $22.02 \pm 0.367^{\mathrm{a}}$ & CS-B & $23.62 \pm 0.302^{\mathrm{a}}$ & CSEO-B & $22.01 \pm 0.369^{\mathrm{a}}$ \\
EO-C & $22.69 \pm 0.257^{\mathrm{a}}$ & CS-C & $23.69 \pm 0.320^{\mathrm{a}}$ & CSEO-C & $22.69 \pm 0.257^{\mathrm{b}}$ \\
EO-D & $23.26 \pm 0.308^{\mathrm{a}}$ & CS-D & $23.87 \pm 0.283^{\mathrm{a}}$ & CSEO-D & $23.26 \pm 0.308^{\mathrm{a}, \mathrm{b}}$ \\
EO-E & $22.31 \pm 0.316^{\mathrm{a}}$ & CS-E & $24.52 \pm 0.283^{\mathrm{a}}$ & CSEO-E & $22.31 \pm 0.316^{\mathrm{a}, \mathrm{b}}$ \\
Control & $21.88 \pm 0.499^{\mathrm{a}}$ & Control & $23.59 \pm 0.250^{\mathrm{a}}$ & Control & $21.88 \pm 0.499^{\mathrm{a}, \mathrm{b}}$ \\
\hline
\end{tabular}

Data, followed by their standard errors, are means of at least fifty measurements. Treatment means were separated using the Tukey test $(P>0.05)$. Different letters in superscript (in each column) indicate significant differences $(P<0.05)$.

cytoplasmic content [45]. Based on this, it is possible to assume that the antifungal effect of essential oils varies according to the source, the concentration applied, and fungal species under study.

In the case of treatments based on chitosan nanoparticles, CS-A, CS-B, CS-C, CS-D, and CS-E, no significant differences in the diameter of spores $(P>0.05)$ compared to control (Figure 5, Table 4) were found. For the effect of chitosan/pepper tree bionanocomposites on the morphometry of the fungus, there was no significant difference between treatments CSEO-A, CSEO-D, and CSEO-E, compared to control. The average diameters of the spores treated with CSEO-B and CSEO-C were statistically different to other treatments. Probably, the concentration of chitosan nanoparticles used in this study was not sufficient to affect the average diameter of the spores, as previous studies have shown that chitosan, both in solution and in nanoparticles, can cause warping and swelling of spores and hyphae. For example, Plascencia-Jatomea et al. [47] evaluated chitosan solutions of average molecular weight $(3.5 \mathrm{~g} / \mathrm{L})$ in the germination of spores of Aspergillus niger, finding anomalies in the membrane and deformation of spores and hyphae. Also, it has been reported that chitosan nanoparticles $\left(5 \times 10^{-3} \mathrm{~g} / \mathrm{mL}\right)$ exhibited antifungal effect on $A$. parasiticus [48], which was attributed to the increase in the contact area due to the small size of nanoparticles, which can be capable of penetrating into the cell and interact with vital components to the growth of fungus. Furthermore, the mode of action of chitosan can be explained in terms of its cationic nature, which can allow electrostatic interaction with proteins and phospholipids of the plasmatic membrane of the microorganism.

\section{Conclusions}

The essential oil extracted from pepper tree leaves (Schinus molle) can be coupled to chitosan in form of bionanocomposites by nanoprecipitation. Although pepper tree oil and chitosan nanoparticles do not diminish the amount of viable spores of Aspergillus parasiticus in vitro significantly, the chitosan/pepper tree bionanocomposites are effective in reducing the number of viable spores. These results indicate that the inclusion of pepper tree essential oils in chitosan bionanocomposites is an alternative that preserves the antifungal properties of both components, decreasing the tendency to volatilization of the essential oil and the consequent loss of activity.
The strategy of applying nanotechnology to the development of new "green biocomposites" with antifungal activity against filamentous fungi important in food and agricultural interest is a promising alternative, which can help to reduce the impact associated with the increased use of synthetic agrochemicals responsible for damage to both human health and the environment.

It is necessary to standardize methodologies for the extraction of essential oils from plants, as well as the isolation of major bioactive compounds that exhibit activity against bacteria, yeasts, and fungi. Moreover, assess its engagement with bio-based polymeric materials shaped as nanoparticle systems. The study of the environmental impact associated with toxicity, possible interactions with biota and microbiota, and the clarification of the possible implications of bio-based polymeric nanoparticles' effects on both agricultural fields and human health are topics that need to be evaluated to ensure safety of these systems.

\section{Conflict of Interests}

The authors declare that there is no conflict of interests regarding the publication of this paper.

\section{References}

[1] V. Saharan, A. Mehrotra, R. Khatik, P. Rawal, S. S. Sharma, and A. Pal, "Synthesis of chitosan based nanoparticles and their in vitro evaluation against phytopathogenic fungi," International Journal of Biological Macromolecules, vol. 62, pp. 677-683, 2013.

[2] M. Razzaghi-Abyaneh, M. Shams-Ghahfarokhi, T. Yoshinari et al., "Inhibitory effects of Satureja hortensis L. essential oil on growth and aflatoxin production by Aspergillus parasiticus," International Journal of Food Microbiology, vol. 123, no. 3, pp. 228-233, 2008.

[3] W.-R. Diao, Q.-P. Hu, S.-S. Feng, W.-Q. Li, and J.-G. Xu, "Chemical composition and antibacterial activity of the essential oil from green huajiao (Zanthoxylum schinifolium) against selected foodborne pathogens," Journal of Agricultural and Food Chemistry, vol. 61, no. 25, pp. 6044-6049, 2013.

[4] E. C. Rosas-Burgos, M. O. Cortez-Rocha, F. J. Cinco-Moroyoqui et al., "Antifungal activity in vitro of Baccharis glutinosa and Ambrosia confertiflora extracts on Aspergillus flavus, Aspergillus parasiticus and Fusarium verticillioides," World Journal of Microbiology and Biotechnology, vol. 25, no. 12, pp. 2257-2261, 2009.

[5] I. Bettaieb, S. Bourgou, W. A. Wannes, I. Hamrouni, F. Limam, and B. Marzouk, "Essential oils, phenolics, and antioxidant 
activities of different parts of cumin (Cuminum cyminum L.)," Journal of Agricultural and Food Chemistry, vol. 58, no. 19, pp. 10410-10418, 2010.

[6] Â. Pawlowski, E. Kaltchuk-Santos, C. A. Zini, E. B. Caramão, and G. L. G. Soares, "Essential oils of Schinus terebinthifolius and S. molle (Anacardiaceae): mitodepressive and aneugenic inducers in onion and lettuce root meristems," South African Journal of Botany, vol. 80, pp. 96-103, 2012.

[7] A. López, S. Castro, M. J. Andina et al., "Insecticidal activity of microencapsulated Schinus molle essential oil," Industrial Crops and Products, vol. 53, pp. 209-216, 2014.

[8] K. Olafsson, J. W. Jaroszewski, U. W. Smitt, and U. Nyman, "Isolation of angiotensin converting enzyme (ACE) inhibiting triterpenes from Schinus molle," Planta Medica, vol. 63, no. 4, pp. 352-355, 1997.

[9] A. Rhouma, H. Ben Daoud, S. Ghanmi, H. ben Salah, M. Romdhane, and M. Demak, "Antimicrobial activities of leaf extracts of Pistacia and Schinus species against some plant pathogenic fungi and bacteria," Journal of Plant Pathology, vol. 91, no. 2, pp. 339-345, 2009.

[10] A. Dikshit, A. A. Nanqvi, and A. Husain, "Schinus molle: a new source of natural fungitoxicant," Applied and Environmental Microbiology, vol. 51, no. 5, pp. 1085-1088, 1986.

[11] M. D. R. Martins, S. Arantes, F. Candeias, M. T. Tinoco, and J. Cruz-Morais, "Antioxidant, antimicrobial and toxicological properties of Schinus molle L. essential oils," Journal of Ethnopharmacology, vol. 151, no. 1, pp. 485-492, 2014.

[12] B. A. Alanís-Garza, G. M. González-González, R. SalazarAranda, N. Waksman de Torres, and V. M. Rivas-Galindo, "Screening of antifungal activity of plants from the northeast of Mexico," Journal of Ethnopharmacology, vol. 114, no. 3, pp. 468471, 2007.

[13] A. Huerta, I. Chiffelle, K. Puga, F. Azúa, and J. E. Araya, "Toxicity and repellence of aqueous and ethanolic extracts from Schinus molle on elm leaf beetle Xanthogaleruca luteola," Crop Protection, vol. 29, no. 10, pp. 1118-1123, 2010.

[14] M. Beyki, S. Zhaveh, S. T. Khalili et al., "Encapsulation of Mentha piperita essential oils in chitosan-cinnamic acid nanogel with enhanced antimicrobial activity against Aspergillus flavus," Industrial Crops and Products, vol. 54, pp. 310-319, 2014.

[15] J. L. de Oliveira, E. V. R. Campos, M. Bakshi, P. C. Abhilash, and L. F. Fraceto, "Application of nanotechnology for the encapsulation of botanical insecticides for sustainable agriculture: prospects and promises," Biotechnology Advances, vol. 32, no. 8, pp. 1550-1561, 2014.

[16] S. Woranuch and R. Yoksan, "Eugenol-loaded chitosan nanoparticles: I. Thermal stability improvement of eugenol through encapsulation," Carbohydrate Polymers, vol. 96, no. 2, pp. 578-585, 2013.

[17] E. F. de Oliveira, H. C. B. Paula, and R. C. M. D. Paula, "Alginate/cashew gum nanoparticles for essential oil encapsulation," Colloids and Surfaces B: Biointerfaces, vol. 113, pp. 146-151, 2014.

[18] S. T. Khalili, A. Mohsenifar, M. Beyki et al., "Encapsulation of Thyme essential oils in chitosan-benzoic acid nanogel with enhanced antimicrobial activity against Aspergillus flavus," LWT_Food Science and Technology, vol. 60, no. 1, pp. 502-508, 2015.

[19] E. D. Herculano, H. C. de Paula, E. A. de Figueiredo, F. G. Dias, and V. d. Pereira, "Physicochemical and antimicrobial properties of nanoencapsulated Eucalyptus staigeriana essential oil," LWT_Food Science and Technology, vol. 61, no. 2, pp. 484491, 2015.
[20] R. Harris, E. Lecumberri, I. Mateos-Aparicio, M. Mengíbar, and A. Heras, "Chitosan nanoparticles and microspheres for the encapsulation of natural antioxidants extracted from Ilex paraguariensis," Carbohydrate Polymers, vol. 84, no. 2, pp. 803806, 2011.

[21] J.-S. Lee, G.-H. Kim, and H. G. Lee, "Characteristics and antioxidant activity of elsholtzia splendens extract-loaded nanoparticles," Journal of Agricultural and Food Chemistry, vol. 58, no. 6, pp. 3316-3321, 2010.

[22] S. F. Hosseini, M. Zandi, M. Rezaei, and F. Farahmandghavi, "Two-step method for encapsulation of oregano essential oil in chitosan nanoparticles: preparation, characterization and in vitro release study," Carbohydrate Polymers, vol. 95, no. 1, pp. 50-56, 2013.

[23] L. Keawchaoon and R. Yoksan, "Preparation, characterization and in vitro release study of carvacrol-loaded chitosan nanoparticles," Colloids and Surfaces B: Biointerfaces, vol. 84, no. 1, pp. 163-171, 2011.

[24] S. Woranuch and R. Yoksan, "Eugenol-loaded chitosan nanoparticles: II. Application in bio-based plastics for active packaging," Carbohydrate Polymers, vol. 96, no. 2, pp. 586-592, 2013.

[25] M. Rinaudo, "Chitin and chitosan: properties and applications," Progress in Polymer Science, vol. 31, no. 7, pp. 603-632, 2006.

[26] A. G. Luque-Alcaraz, J. Lizardi, F. M. Goycoolea et al., "Characterization and antiproliferative activity of nobiletin-loaded chitosan nanoparticles," Journal of Nanomaterials, vol. 2012, Article ID 265161, 7 pages, 2012.

[27] L. Y. Ing, N. M. Zin, A. Sarwar, and H. Katas, "Antifungal activity of chitosan nanoparticles and correlation with their physical properties," International Journal of Biomaterials, vol. 2012, Article ID 632698, 9 pages, 2012.

[28] A. Mohammadi, M. Hashemi, and S. M. Hosseini, "Nanoencapsulation of Zataria multiflora essential oil preparation and characterization with enhanced antifungal activity for controlling Botrytis cinerea, the causal agent of gray mould disease," Innovative Food Science \& Emerging Technologies, vol. 28, pp. 73-80, 2015.

[29] C. Dima, M. Cotârlet, P. Alexe, and S. Dima, "Microencapsulation of essential oil of pimento [Pimenta dioica (L) Merr.] by chitosan/k-carrageenan complex coacervation method," Innovative Food Science \& Emerging Technologies, vol. 22, pp. 203211, 2014.

[30] J. Meletiadis, J. W. Mouton, J. F. G. M. Meis, B. A. Bouman, J. P. Donnelly, and P. E. Verweij, "Colorimetric assay for antifungal susceptibility testing of Aspergillus species," Journal of Clinical Microbiology, vol. 39, no. 9, pp. 3402-3408, 2001.

[31] A. P. Martínez-Camacho, M. O. Cortez-Rocha, J. M. EzquerraBrauer et al., "Chitosan composite films: thermal, structural, mechanical and antifungal properties," Carbohydrate Polymers, vol. 82, no. 2, pp. 305-315, 2010.

[32] F. Chen, Z. Shi, K. G. Neoh, and E. T. Kang, "Antioxidant and antibacterial activities of eugenol and carvacrol-grafted chitosan nanoparticles," Biotechnology and Bioengineering, vol. 104, no. 1, pp. 30-39, 2009.

[33] X. Jin, J. Wang, and J. Bai, "Synthesis and antimicrobial activity of the Schiff base from chitosan and citral," Carbohydrate Research, vol. 344, no. 6, pp. 825-829, 2009.

[34] F.-L. Yang, X.-G. Li, F. Zhu, and C.-L. Lei, "Structural characterization of nanoparticles loaded with garlic essential oil and their insecticidal activity against Tribolium castaneum (Herbst) 
(Coleoptera: Tenebrionidae)," Journal of Agricultural and Food Chemistry, vol. 57, no. 21, pp. 10156-10162, 2009.

[35] H. Zhang and Y. Zhao, "Preparation, characterization and evaluation of tea polyphenol-Zn complex loaded $\beta$-chitosan nanoparticles," Food Hydrocolloids, vol. 48, pp. 260-273, 2015.

[36] L. Qi, Z. Xu, X. Jiang, C. Hu, and X. Zou, "Preparation and antibacterial activity of chitosan nanoparticles," Carbohydrate Research, vol. 339, no. 16, pp. 2693-2700, 2004.

[37] W. Fan, W. Yan, Z. Xu, and H. Ni, "Formation mechanism of monodisperse, low molecular weight chitosan nanoparticles by ionic gelation technique," Colloids and Surfaces B: Biointerfaces, vol. 90, no. 1, pp. 21-27, 2012.

[38] C. A. Clausen and V. W. Yang, "Colorimetric micro-assay for accelerated screening of mould inhibitors," International Biodeterioration \& Biodegradation, vol. 77, pp. 68-71, 2013.

[39] P. D. Khot, P. A. Suci, and B. J. Tyler, "Candida albicans viability after exposure to amphotericin B: assessment using metabolic assays and colony forming units," Journal of Microbiological Methods, vol. 72, no. 3, pp. 268-274, 2008.

[40] A. G. Al-Bakri and F. U. Afifi, "Evaluation of antimicrobial activity of selected plant extracts by rapid XTT colorimetry and bacterial enumeration," Journal of Microbiological Methods, vol. 68, no. 1, pp. 19-25, 2007.

[41] E. Ghasemian, A. Naghoni, B. Tabaraie, and T. Tabaraie, "In vitro susceptibility of filamentous fungi to copper nanoparticles assessed by rapid XTT colorimetry and agar dilution method," Journal de Mycologie Medicale, vol. 22, no. 4, pp. 322-328, 2012.

[42] S. Zhaveh, A. Mohsenifar, M. Beiki et al., "Encapsulation of Cuminum cyminum essential oils in chitosan-caffeic acid nanogel with enhanced antimicrobial activity against Aspergillus flavus," Industrial Crops and Products, vol. 69, pp. 251-256, 2015.

[43] N. M. Zain, A. G. F. Stapley, and G. Shama, "Green synthesis of silver and copper nanoparticles using ascorbic acid and chitosan for antimicrobial applications," Carbohydrate Polymers, vol. 112, pp. 195-202, 2014.

[44] I. Rasooli and M. R. Abyaneh, "Inhibitory effects of Thyme oils on growth and aflatoxin production by Aspergillus parasiticus," Food Control, vol. 15, no. 6, pp. 479-483, 2004.

[45] C. Y. Kohiyama, M. M. Yamamoto Ribeiro, S. A. G. Mossini et al., "Antifungal properties and inhibitory effects upon aflatoxin production of Thymus vulgaris L. by Aspergillus flavus Link," Food Chemistry, vol. 173, pp. 1006-1010, 2015.

[46] E. M. Soylu, S. Soylu, and S. Kurt, "Antimicrobial activities of the essential oils of various plants against tomato late blight disease agent Phytophthora infestans," Mycopathologia, vol. 161, no. 2, pp. 119-128, 2006.

[47] M. Plascencia-Jatomea, G. Viniegra, R. Olayo, M. M. CastilloOrtega, and K. Shirai, "Effect of chitosan and temperature on spore germination of Aspergillus niger," Macromolecular Bioscience, vol. 3, no. 10, pp. 582-586, 2003.

[48] O. Cota-Arriola, M. O. Cortez-Rocha, J. M. Ezquerra-Brauer et al., "Ultrastructural, morphological, and antifungal properties of micro and nanoparticles of chitosan crosslinked with sodium tripolyphosphate," Journal of Polymers and the Environment, vol. 21, no. 4, pp. 971-980, 2013. 

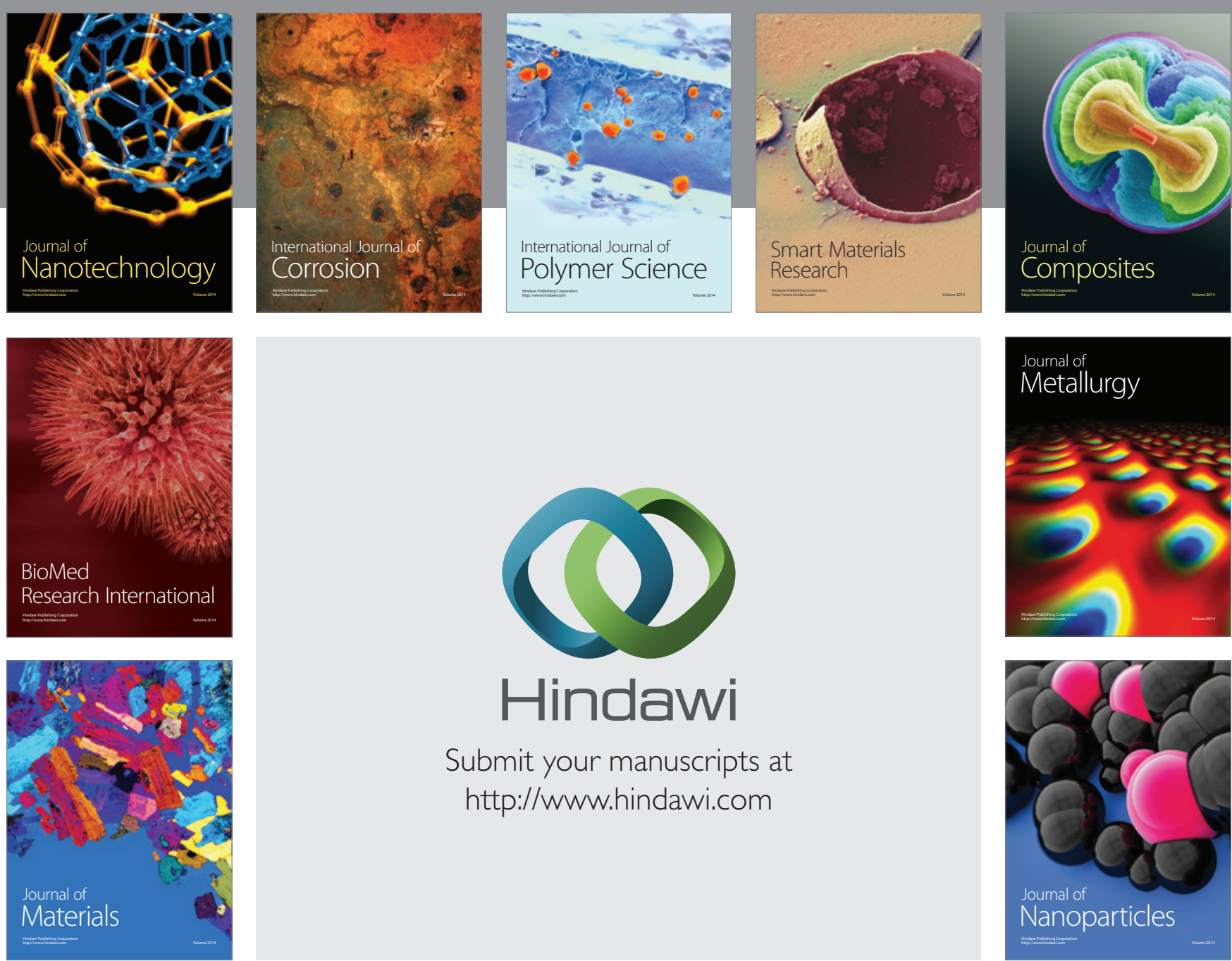

\section{Hindawi}

Submit your manuscripts at

http://www.hindawi.com

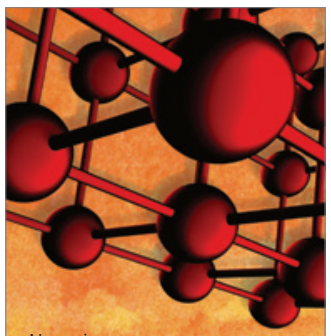

Materials Science and Engineering
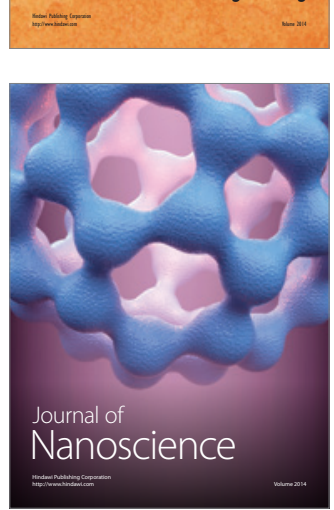
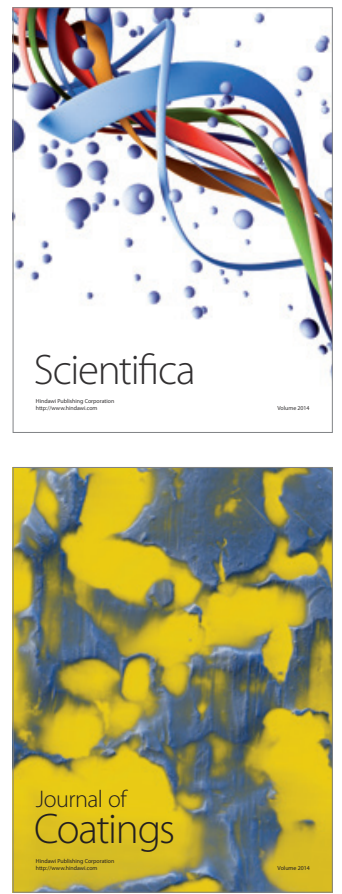
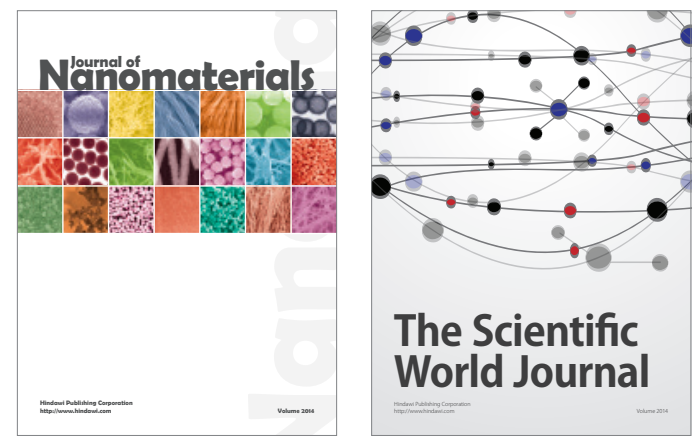

The Scientific World Journal
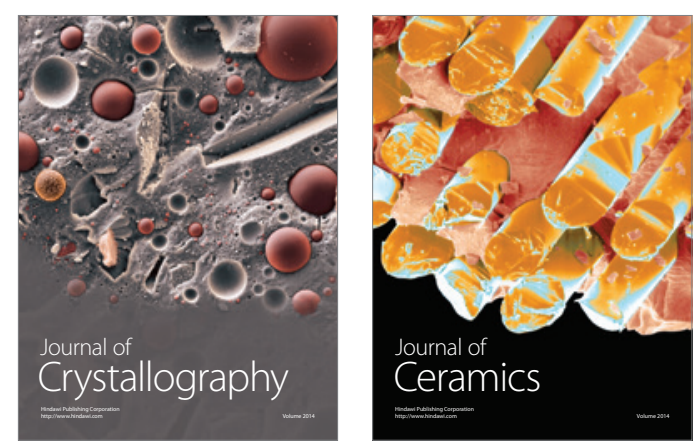
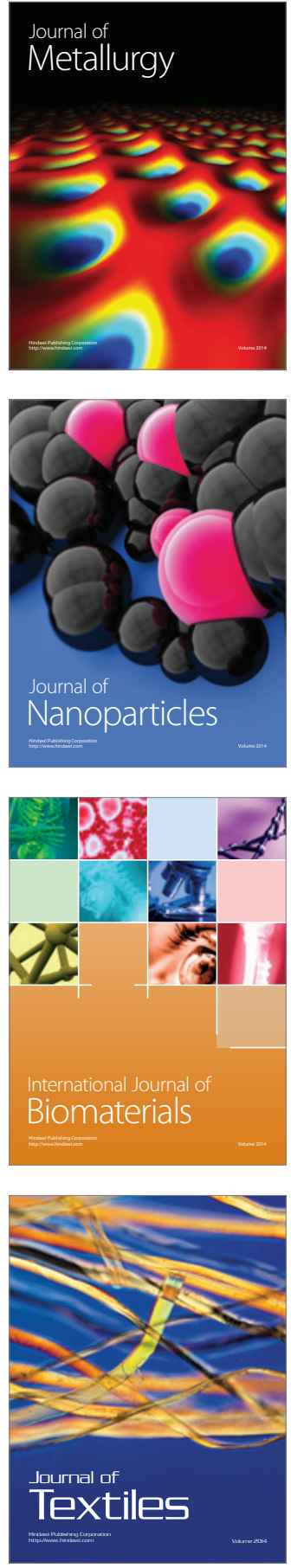